\title{
Marcuse e o conceito de trabalho ${ }^{1}$
}

\author{
Josué Pereira da Silva²
}

\begin{abstract}
Resumo: Este artigo discute o conceito de trabalho em Herbert Marcuse, tema importante em sua produção teórica, assim como na de outros teóricos críticos frankfurtianos. As formulações de Marcuse sobre o tema mantém forte relação com a concepção de trabalho de Marx, segundo a qual o trabalho desempenha papel fundamental na constituição do ser humano. Por outro lado, seus escritos exerceram grande influência sobre movimentos sociais que, entre outras coisas, contestam a centralidade do trabalho na sociedade contemporânea. Além disso, sua discussão do trabalho alienado em Razão e revolução, inspirada nos Grundrisse de Marx, antecipa o debate atual sobre a emergência do imaterial.
\end{abstract}

Palavras-chave: H. Marcuse; Trabalho; Teoria Crítica; K. Marx; G. W. F. Hegel.

\section{Marcuse and the Concept of Labor}

Abstract: This article deals with the concept of labor in Herbert Marcuse. Labor occupies an important place in his theoretical production as well as in that of other theorists from the Frankfurt School. Marcuse's formulations on the subject are strongly related to Marx's concept of labor, according to which labor plays a fundamental role in the constitution of the human being. On the other hand, his writings have exerted great influence on social movements that, among other things, challenge the centrality of labor in contemporary society. Moreover, his discussion of alienated labor in Reason and Revolution, inspired in Marx's Grundrisse, anticipates the current debate on the emergence of the immaterial.

Key-words: H. Marcuse; Labor; Critical Theory; K. Marx; G. W. F. Hegel.

Marcuse y el concepto de trabajo

Resumen: Este artículo examina el concepto de trabajo en Herbert Marcuse, tema importante en su producción teórica, así como en la de otros teóricos críticos frankfurtianos. Las formulaciones de Marcuse sobre este tema presentan una estrecha relación con la concepción de trabajo de Marx, según la cual el trabajo juega un papel

\footnotetext{
${ }^{1}$ Recebido em 15/08/2016 e aprovado em 17/02/2017.

${ }^{2}$ Professor do Departamento de Sociologia da Universidade Estadual de Campinas (UNICAMP). Contato: josueps@unicamp.br.
} 
$|22|$

Marcuse e o conceito de trabalho

fundamental en la constitución del ser humano. Por otra parte, sus escritos ejercen una gran influencia sobre los movimientos sociales que, entre otras cosas, cuestionan la centralidad del trabajo en la sociedad contemporánea. Además, su discusión sobre el trabajo alienado en Razón y revolución, inspirada en los Grundrisse de Marx, anticipa el debate actual sobre el surgimiento de lo inmaterial.

Palabras clave: H. Marcuse; Trabajo; Teoría crítica; K. Marx; G. W. F. Hegel.

Meu objetivo com este artigo é discutir o conceito de trabalho em alguns dos escritos de Herbert Marcuse. Escolhi esse tema, primeiro porque o conceito de trabalho ocupa um lugar importante na sua produção teórica e, segundo, porque alguns de seus escritos parecem ter exercido grande influência sobre movimentos sociais que, entre outras coisas, contestam a centralidade do trabalho na sociedade contemporânea. ${ }^{3}$ Ademais, o trabalho sempre ocupou um lugar de destaque nas formulações dos teóricos críticos frankfurtianos, dos quais Marcuse é tido como uma das figuras mais importantes (SILVA, 2008, p. 35-52).

As formulações de Marcuse a respeito do conceito de trabalho mantêm forte relação com a concepção de trabalho de Marx, segundo a qual o trabalho desempenha papel fundamental na constituição de ser humano, sendo por meio dele que os humanos se diferenciam dos animais.

Marcuse lida com o problema do trabalho em vários de seus escritos, mas ele discute o tema em profundidade em três textos: os artigos "The Foundation of Historical Materialism" (MARCUSE, 1983), e "On the Philosophical Foundations of the Concept of Labor in Economics" (1973), ${ }^{4}$ e o livro Reason and Revolution (1960). Além desses três textos, que serão as principais fontes deste artigo, também me apoio no livro Soviet Marxism (1958), sobretudo porque Marcuse discute o mesmo problema no contexto de uma sociedade não capitalista, ou seja, em um contexto diferente daquele no qual Marx escreveu.

\footnotetext{
${ }^{3}$ Em relação à influência de Marcuse sobre os movimentos políticos dos anos 1960 e 1970, ver Douglas Kellner (1984), p. 1-12.

${ }^{4}$ Ver também: Kellner (1973).
} 
Neste artigo, eu começo mostrando como Marcuse explica a maneira pela qual o trabalho aparece como um conceito ontológico na teoria de Marx e como o próprio Marcuse aborda e define tal conceito (I). Em seguida, discuto como Marcuse analisa o problema do trabalho alienado e seu vínculo com a teoria da revolução de Marx (II). Em terceiro lugar, mostrarei como para Marcuse a teoria da revolução de Marx está vinculada à abolição do trabalho (III). E, em quarto lugar, à luz da discussão anterior, mostro como Marcuse analisa a concepção soviética de trabalho, e como ele a vê em contradição com a concepção de Marx sobre o trabalho (IV). Por fim, concluo fazendo algumas considerações sobre o lugar do trabalho na Teoria Crítica frankfurtiana e também sobre a contribuição de Marcuse a respeito do tema. ${ }^{5}$

I

Em sua análise do conceito de trabalho, Marcuse assegura que há conexões entre Marx e Hegel no que diz respeito às abordagens de ambos sobre o trabalho e o papel desse último na definição de homem (MARCUSE, 1983, p. 4). Para Marcuse, a análise conceitual avançada por Marx nos Manuscritos econômicos e filosóficos encontra seus primeiros fundamentos na filosofia de Hegel, principalmente na Fenomenologia do espírito, a qual Marx considerava "o verdadeiro ponto de origem e o segredo da filosofia hegeliana" (MARCUSE, 1983, p. 41). ${ }^{6}$

Para tornar claro tal vínculo entre Marx e Hegel no que se refere a esse problema, Marcuse mostra como cada um deles define trabalho. Segundo Marcuse, Hegel definia trabalho como "o fazer [...] no qual 'o puro ser-para-si mesmo da consciência

\footnotetext{
${ }^{5}$ As traduções das citações em língua estrangeira são minhas, embora em um caso eu tenha consultado a tradução brasileira (MARCUSE, 1981).

${ }^{6}$ Diferentemente da posição de Marcuse, Hans-Christoph Schmidt am Busch sustenta que a concepção de trabalho "como um ato de exteriorização do sujeito" foi formulada por Hegel não na Fenomenologia do espírito, mas na Filosofia do espírito (SCHMIDT AM BUSCH, 2005).
} 
projeta-se para fora de si mesmo como elemento de permanência'", e que "esse elemento consciência volta ao si mesmo dando-se ao objeto de trabalho como uma substância" (MARCUSE, 1973, p. 12).

Para Marcuse, Marx incorporou esse "conceito hegeliano de trabalho com todas suas características essenciais". E, para provar o parentesco entre as concepções trabalho de Marx e de Hegel, ele nos fornece a seguinte citação de Marx, na qual a definição de trabalho assemelha-se à de Hegel: "O trabalho é o tornar-se-para-si do homem na externalização [...] ou como homem externalizado; é o ato de autocriação ou auto-objetivação do homem" (MARCUSE, 1973, p. 12).

Obviamente, Marcuse observa que isto não quer dizer que a visão de Marx sobre o problema do trabalho seja uma simples continuação da concepção hegeliana do trabalho. O que Marcuse quer dizer, na verdade, é que "as categorias fundamentais da teoria de Marx emergem de sua empática confrontação com a filosofia de Hegel" (MARCUSE, 1983, p. 4). ${ }^{7}$ Em outras palavras, para ele, o conceito de trabalho de Marx só pode ser compreendido retornando-se ao problema levantado pela filosofia de Hegel, mas ao mesmo tempo Marx faz isto criticando Hegel.

Por outro lado, é preciso dizer que, segundo Marcuse, não só a filosofia de Hegel, mas também o humanismo teorizado por Feuerbach exerceu influência sobre a concepção de trabalho de Marx. ${ }^{8}$ Dessa forma, ele assegura que foi inicialmente por meio da crítica humanista e naturalista que Marx chegou à definição

\footnotetext{
7 O próprio Marx enfatiza sua discordância com Hegel pelo fato deste último, nas palavras de Marx, "apreender o trabalho como a essência - como a essência do homem no ato de prover a si mesmo: ele vê apenas o lado positivo do trabalho, mas não seu lado negativo. O trabalho é o tornar-se ser para o si mesmo do homem na alienação, ou como homem alienado. $\mathrm{O}$ único trabalho que Hegel conhece e reconhece é o trabalho mentalmente abstrato" (MARX, 1978).

${ }^{8}$ Sobre a complexidade do conceito de trabalho em Marx, ver também o importante artigo de R. N. Berki, "On the Nature and Origins of Marx's Concept of Labor" (BERKI, 1979).
} 
da essência humana. Para tornar isto mais claro, Marcuse cita as seguintes palavras de Marx:

\begin{abstract}
O homem é um ser genérico, não somente na medida em que torna seu objeto, teórica e praticamente, o gênero, tanto o seu como o de outras coisas - e isto é apenas outra expressão para a mesma coisa - mas também na medida em que se relaciona consigo mesmo como gênero real, vivo, porque se relaciona consigo mesmo como um ser universal e, portanto, livre (MARX apud MARCUSE, 1983, p. 15).
\end{abstract}

De acordo com Marcuse, essas palavras são muito importantes porque elas revelam "a real origem do conceito de 'gênero' de Marx", isto é, a definição de homem como um ser genérico ou um ser que tem o gênero como seu objeto.

É devido a tal definição de homem que ele pode ser concebido como ser capaz de explorar, moldar, tratar e produzir "qualquer ser segundo seu padrão inerente". É aqui que o trabalho aparece como atividade humana específica porque é por meio do trabalho que o homem é provido com a habilidade para se relacionar com sua própria espécie e tornar-se livre. Neste sentido, trabalho significa liberdade.

Marcuse escreve então que "o homem como um ser genérico é um ser universal" e também que "sua existência é uma relação universal com a objetividade", mas ele, o homem, "não pode simplesmente aceitar o mundo objetivo" como este aparece para ele (MARCUSE, 1983, p. 16). Pelo contrário, ele pode e deve transformar os objetos deste mundo e é apenas nessa capacidade de modificar o mundo objetivo que reside sua potencialidade de ser livre:

Ele pode "confrontar" qualquer objeto e esgotar e realizar suas possibilidades intrínsecas em seu trabalho. Ele pode produzir "de acordo com as leis da beleza" e não meramente de acordo com o padrão de suas necessidades (MARCUSE, 1983, p. 17). 
$|26|$

Marcuse e o conceito de trabalho

É neste sentido que o trabalho, como uma atividade humana livre, aparece na teoria de Marx como uma categoria ontológica (MARCUSE, 1983, p. 25).

Esta definição de homem parece fundada em duas importantes suposições. Uma, que vê o homem como um ser sensível, refere-se às circunstâncias dadas, isto é, ao mundo objetivo que age sobre ele; e outra suposição que concebe o homem como um sujeito livre, que por meio de sua atividade livre - o trabalho - pode modificar as circunstâncias dadas, acima referidas. Segundo Marcuse, a primeira suposição provavelmente refere-se à influência das teorias de Feuerbach em Marx; a segunda suposição indica a herança em Marx da filosofia hegeliana. Mas, para Marcuse, a abordagem de Marx não pode ser confundida com a abordagem de Feuerbach, nem com a de Hegel.

Assim, afirma Marcuse, o conflito na essência humana se dá, de um lado, porque o homem "como um ser natural, corpóreo, sensível, objetivo é uma criatura passiva, condicionada e limitada" (MARCUSE, 1983, p. 20); e, de outro lado, porque a práxis humana (isto é, o trabalho) faz dele um ser ativo. Portanto, a totalidade da existência humana decorre do fato de sua situação no mundo caracterizar-se por ser ao mesmo tempo ativa e passiva, no sentido de que o homem faz sua própria história, porém sob as circunstâncias dadas pelo mundo existente, objetificado. ${ }^{9}$

Segundo Marcuse, "a definição do homem como um mero ser passivo 'com necessidades' é a base original para a crítica de Feuerbach a Hegel e sua ideia de um homem puramente livre, criativo e consciente" (MARCUSE, 1983, p. 20). Essa mesma tendência de conceber o homem como um ser sensível, passivo, “definido pelas necessidades e por sua dependência em relação à

\footnotetext{
${ }^{9}$ Ver, a propósito, Marx, em The Eighteenth Brumaire of Louis Bonaparte: "Os homens fazem sua própria história, mas eles não a fazem como gostariam; eles não a fazem em circunstâncias por eles escolhidas, mas em circunstâncias diretamente encontradas, dadas e transmitidas do passado" (MARX, 1969, p. 15).
} 
objetividade pré-estabelecida" (MARCUSE, 1983, p. 20), é discernível também em Marx.

Mas em Marx, diferentemente de Feuerbach, o conceito de sensibilidade é modificado pela inserção dos "traços básicos da existência prática e social". É daí que vem o conceito de práxis humana, que, segundo Marcuse, "constitui a linha de demarcação entre" Marx e Feuerbach (MARCUSE, 1983, p. 21). Para tornar clara essa diferença, Marcuse escreve as seguintes palavras:

Em Feuerbach, a apropriação humana do mundo e sua relação com o mundo permanece essencialmente teórica, e isto se expressa no fato de que a forma de relação, a qual permite a apropriação da realidade, é "a percepção". Em Marx [...] o trabalho substitui essa percepção, embora a importância central da relação teórica não desapareça: ela é combinada com o trabalho na relação de interpretação dialética (MARCUSE, 1983, p. 22).

\section{II}

O trabalho, como mostrado acima, é a expressão real da liberdade porque é por meio do trabalho que o homem se torna livre. Mas, por outro lado, alienação e estranhamento ditam também a condição real do homem em decorrência das circunstâncias do trabalho na facticidade histórica do capitalismo. Aqui o trabalho não é mais "atividade livre" ou autorrealização universal e livre do homem, mas sim sua escravização e perda de realidade (cf. MARCUSE, 1983, p. 26; 1960, p. 277).

Ao analisar a abordagem de Marx sobre o problema do trabalho alienado, Marcuse assegura que da descrição de Marx podemos descobrir que o que ele descreve "não é meramente um assunto econômico", porque a alienação do trabalho é também alienação do homem (MARCUSE, 1983, p. 7). Assim, na teoria de Marx o homem é tratado como um homem e não meramente como um trabalhador, como ocorre na economia política burguesa. Na concepção de Marx, portanto, o processo de alienação não deve 
ser visto como um problema de história econômica, mas sim como um processo que abrange o todo da realidade humana; ou seja, alienação refere-se à totalidade do homem e de sua realidade.

Precisamente neste ponto reside a crítica de Marx à economia política. Segundo Marcuse, a economia política é criticada por Marx exatamente porque ela fornece a justificação científica do "estranhamento e desvalorização da realidade humana representada na sociedade capitalista" (MARCUSE, 1983, p. 5). Na concepção de Marx, a economia política aparece como a ciência que trata o homem como algo não essencial, justamente porque ela sanciona cientificamente "a perversão do mundo histórico-social do homem em mundo alienado do dinheiro e das mercadorias" (MARCUSE, 1983, p. 5).

É por meio da crítica da economia política burguesa, que não reconhece a alienação e o estranhamento, que Marx começa "a descrição das circunstâncias da alienação e do estranhamento" (MARCUSE, 1983, p. 7). Mas é exatamente porque alienação e estranhamento não são "fatos econômicos" - no sentido que a economia política burguesa os reconhece (por exemplo, renda da terra ou preço das mercadorias) - que sua crítica só é possível como crítica filosófica. É o que Marx faz ao desenvolver o conceito de trabalho (cf. MARCUSE, 1973; 1983; 1960).

A ideia de trabalho alienado está intrinsecamente relacionada com a ideia de propriedade privada. E é dessa relação que Marx deriva sua teoria da revolução. Segundo Marcuse, Marx exemplifica o trabalho alienado primeiramente pela separação entre o trabalhador e o produto de seu trabalho, e secundariamente pela relação do trabalhador com sua atividade (MARCUSE, 1960, p. 276).

A separação entre o trabalhador e o produto de seu trabalho resulta diretamente da particular condição de propriedade privada existente sob o capitalismo, que transforma o produto do trabalho em mercadorias, em propriedade do capital: "capital é o poder de dispor sobre os produtos do trabalho" (MARCUSE, 1960, p. 276). Por outro lado, como capital é nada mais que trabalho morto, nesse processo o trabalho "torna-se a vítima de um poder" criado por 
ele mesmo, e o trabalhador, alienado do produto de seu trabalho, torna-se ele próprio um homem alienado. Assim, ele assume, citando Marx, que "a objetificação aparece como perda do objeto e escravização pelo objeto, e a apropriação aparece como alienação e expropriação" (MARCUSE, 1960, p. 276).

Em suma, trabalho alienado e propriedade privada aparecem diretamente relacionados um ao outro, o primeiro entendido como a relação externa do homem com a natureza e consigo próprio, e a última como um resultado do trabalho alienado (MARCUSE, 1983, p. 11)

Nas palavras de Marcuse, essa relação entre trabalho alienado e propriedade privada é descrita como segue:

\begin{abstract}
A negatividade da sociedade capitalista reside em sua alienação do trabalho; a negação dessa negatividade virá com a abolição do trabalho alienado. A alienação adquiriu sua forma mais universal na instituição da propriedade privada; a reparação será feita com a abolição da propriedade privada (MARCUSE, 1960, p. 282).
\end{abstract}

A conexão intrínseca entre trabalho alienado e propriedade privada, e a necessidade de sua abolição, fornecem, segundo Marcuse, a base para a teoria da revolução de Marx (MARCUSE, 1983 , p. 29; 1960, p. 282).

\title{
III
}

A teoria da revolução de Marx, ou a necessidade da práxis revolucionária, resulta assim de sua interpretação da realidade histórica concreta do capitalismo na qual a alienação e o estranhamento da essência humana se expressam na alienação e no estranhamento do trabalho. Por causa dessa "total perversão e ocultação" da essência do homem e do trabalho humano, o trabalho não é mais "atividade livre ou a autorrealização universal e livre do homem, mas sim sua escravidão e perda de realidade" (MARCUSE, 1983, p. 26) 
$|30|$

Marcuse e o conceito de trabalho

Consequentemente, a essência humana não pode mais ser encontrada em sua totalidade no trabalhador, uma vez que este último em tal situação é "uma não-pessoa". Portanto, fundada no trabalho estranhado, a atividade humana não é mais o meio para a autorrealização do homem, mas apenas uma luta pela mera existência: "o que é animal se torna humano e o que é humano se torna animal" (MARCUSE, 1983, p. 27).

Segundo Marcuse, essa reificação ${ }^{10}$ afeta não só o trabalhador; ela afeta todos os estratos da sociedade, incluindo o capitalista:

\begin{abstract}
A "dominação da matéria morta sobre o homem" revela-se para o capitalista no estado da propriedade privada e na forma pela qual ele a tem e possui. É na realidade um estado de ser possuído, de ser tido, de escravidão a serviço da propriedade. Ele possui sua propriedade não como um campo de livre autorrealização e atividade, mas puramente como capital (MARCUSE, 1983, p. 27).
\end{abstract}

Esta é a facticidade do capitalismo. E a superação desta situação requer a abolição do modo prevalecente de trabalho.

Essas são, segundo Marcuse, as condições dadas pelo trabalho alienado e pela propriedade privada; ambas são partes intrínsecas da facticidade do capitalismo que tornam possível a separação entre essência e existência na realidade humana:

Se essência e existência se tornaram, assim, separadas
e se a tarefa real e livre da praxis humana é a unificação
de ambas como realização factual, então a tarefa
autêntica, quando a facticidade progrediu de forma
a perverter totalmente a essência humana, é a abolição
radical dessa facticidade (MARCUSE, 1983, p. 29).

${ }^{10}$ Sobre o tema da reificação em Marcuse, ver seu texto "The Obsolescence of the Freudian Concept of Man" (MARCUSE, 1970, p. 44-61). Ver também Vandenberghe (1998) e Loureiro (2009). 
É, portanto, na necessidade de transcender esta situação que reside o inexorável impulso para revolucionar a realidade factual do capitalismo. Assim, a teoria da revolução de Marx implica tanto a abolição da propriedade privada quanto a do trabalho alienado.

Na concepção de Marx, escreve Marcuse, há duas formas de propriedade privada: uma forma estranhada e uma forma verdadeira. A primeira é uma propriedade que é meramente privada, a segunda uma propriedade que é verdadeiramente humana. Marcuse assegura então que a verdadeira propriedade, na concepção de Marx, é "a disponibilidade e usabilidade de todos os objetos que o homem necessita para a livre realização de sua essência", enquanto "a propriedade privada consiste em um falso modo de ter e possuir objetos" (MARCUSE, 1983, p. 32).

A propriedade falsa é um tipo de apropriação "unilateral" limitada somente ao comportamento físico do homem, e de objetos, que podem ser transformados em capital. A propriedade verdadeira, ao contrário, é plurilateral por implicar a apropriação da totalidade da essência humana.

Por envolver o todo do homem, a revolução para superar a propriedade privada, assim como o trabalho alienado (ambos estão intrinsecamente conectados), é mais que um simples evento econômico. Mais que isto: ela será a libertação da sociedade que abrirá o caminho para o retorno do homem à sua essência social. Marcuse acrescenta: "Não é, todavia, o indivíduo isolado ou uma pluralidade abstrata de indivíduos que se realiza, mas sim o homem social, o homem como um ser social" (MARCUSE, 1983, p. 33).

A realização da essência humana requer assim a total reversão da situação existente. Essa transformação, caracterizada como revolução comunista, deve ser universal para que possa reverter a totalidade das condições prevalecentes e estabelecer uma nova ordem universal:

A convulsão revolucionária que acaba com a sociedade capitalista libera todas as potencialidades para a satisfação geral que desenvolveu neste sistema. 
$\mid 32$ |

Marcuse e o conceito de trabalho

\begin{abstract}
Marx apropriadamente chama a revolução comunista de um ato de "apropriação", dando a entender que com a abolição da propriedade privada os homens obterão a verdadeira propriedade sobre todas as coisas que tinham até então lhes permanecido estranhas (MARCUSE, 1960, p. 288).
\end{abstract}

A apropriação, por outro lado, é determinada pelo objeto a ser apropriado e pelas pessoas que o apropriam. O primeiro caso refere-se à relação entre homem e natureza que depois da revolução comunista seguirá "um plano geral formulado por indivíduos livremente reunidos", em vez de operar "como uma força natural cega" como ocorre na sociedade capitalista. O segundo diz respeito ao fato de que "a alienação do trabalho criou uma sociedade dividida em classes opostas" (MARCUSE, 1960, p. 289).

Na sociedade capitalista que é dividida em classes, classe refere-se à unidade social e econômica real, e não ao indivíduo. A existência individual, portanto, não pertence a ele, mas à sua classe. A divisão da sociedade em classes, por outro lado, reside na divisão fundamental em capital e trabalho assalariado da qual deriva a divisão básica da sociedade burguesa em burguesia e proletariado, as duas classes fundamentais da sociedade capitalista.

O proletariado, escreve Marcuse, é distinto porque, como uma classe, significa a negação de todas as classes. Os interesses de todas as outras classes são essencialmente unilaterais; o interesse do proletariado é essencialmente universal. O proletariado não tem propriedade nem lucro a defender. Sua preocupação, a abolição do prevalecente modo de trabalho, é a preocupação da sociedade como um todo (MARCUSE, 1960, p. 291).

Seguindo Marx, Marcuse afirma que a universalidade do proletariado é negativa porque a alienação do trabalho nega 
ao proletário qualquer possibilidade de autorrealização no trabalho: "seu trabalho nega sua existência inteira" (MARCUSE, 1960, p. 291).

Dessa forma, a abolição do trabalho alienado implica a abolição do proletariado, e a abolição do trabalho como tal. Assim, escreve Marcuse,

\begin{abstract}
A questão não é a libertação do trabalho, porque o trabalho já se tornou "livre"; trabalho livre é a realização da sociedade capitalista. O comunismo só pode curar as "doenças" do burguês e o infortúnio do proletário "removendo a sua causa, a saber, “o trabalho" (MARCUSE, 1960, p. 292).
\end{abstract}

\title{
IV
}

Vimos nas páginas precedentes como Marcuse lida com o problema do trabalho nos escritos de Marx. Iniciamos mostrando os argumentos de Marcuse, segundo os quais o trabalho é concebido como um conceito ontológico; em seguida passamos ao problema do trabalho alienado na sociedade capitalista, até a necessidade de suplantar a alienação do trabalho - a qual só será possível, conforme a teoria de Marx, por meio de uma revolução social.

Ao longo desta discussão, ficou claro que o trabalho, uma vez assumido como conceito ontológico, vincula-se à própria definição de homem enquanto tal. Porque, segundo essa concepção, é por meio do trabalho que o homem se diferencia dos animais. Consequentemente, considerando este vínculo entre trabalho e homem, a alienação do primeiro implica a alienação do segundo. Assim, libertar o homem da alienação só é possível libertando também o trabalho da alienação.

Por outro lado, Marcuse nos assegura, seguindo as formulações de Marx, que o trabalho já foi tornado "livre" pela sociedade capitalista e que a tarefa da revolução comunista não é sua libertação, mas sua abolição. É interessante notar aqui que a noção de trabalho livre, como mencionado acima (isto é, que "o trabalho livre é uma realização da sociedade capitalista"), 
$|34|$

Marcuse e o conceito de trabalho

significa que, na sociedade capitalista, o trabalho - como trabalho assalariado - é livre se comparado com a servidão e a escravidão. Neste sentido, o trabalhador livre, diferentemente do servo e do escravo, é livre para vender sua força de trabalho ao capitalista. ${ }^{11}$

Isto quer dizer, em outras palavras, que na sociedade capitalista trabalho livre significa trabalho assalariado. Esse trabalho assalariado, enquanto trabalho alienado, clama não por sua libertação, mas sim por sua abolição. E esta última seria tarefa da revolução comunista. ${ }^{12}$

Parece haver nessa discussão uma tensão entre dois conceitos de trabalho. ${ }^{13}$ Um que concebe o trabalho como uma categoria geral, ontológica, que se encontra além da facticidade imediata da sociedade capitalista; e outro que vê o trabalho em uma dada situação histórica do capitalismo, que envolve todas as condições de sua alienação. O primeiro trabalho aparece, em

\footnotetext{
${ }^{11}$ Ver, a respeito, Marx (1978b).

12 Jacques Donzelot, em seu livro L'invention du social, chama a atenção para a diferença de posição de Marx a respeito do trabalho assalariado em escritos como o Manifesto comunista, onde defende a abolição do trabalho assalariado, e A guerra civil em França, quando se coloca em defesa do direito ao trabalho (DONZELOT, 1994, p. 45-49).

${ }^{13}$ Para a distinção entre esses dois tipos de trabalho - aliás, a única referência explícita que encontrei nos escritos de Marcuse - ver o texto a seguir. Ao contestar a tendência de Freud a considerar que o "trabalho fornece a oportunidade para uma 'verdadeira descarrega dos impulsos narcísicos, agressivos, e mesmo eróticos, dos componentes libidinais"', Marcuse diz contestar tal afirmação "porque ela não faz distinção entre trabalho alienado e trabalho não alienado (entre labor e work): o primeiro é, por sua própria natureza, repressivo das potencialidades humanas e, portanto, também repressivo dos 'impulsos dos componentes libidinais' que devem entrar na atividade do trabalho (work)" (MARCUSE, 1966, p. 212). É interessante notar aqui que trabalho (labor), sem o adjetivo alienado, aparece como carga, obrigação, enquanto trabalho (work) pode significar o contrário. Em outras palavras, o trabalho, no sentido de labor, parece ser o trabalho alienado, enquanto o trabalho no sentido de obra (work) parece significar o trabalho não alienado.
} 
Marx como em Marcuse, como pertencendo à própria natureza do homem (homem como animal social). Esse trabalho pertence ao reino da liberdade. ${ }^{14} \mathrm{O}$ segundo trabalho, sendo alienado, deve desaparecer junto com as condições históricas que o criaram. Esse tipo de trabalho pertenceria ao reino da necessidade, e seria abolido pela revolução comunista. ${ }^{15}$ Por isso, é importante ver a crítica de Marcuse ao tratamento soviético do problema do trabalho, que ele considera muito diferente daquele encontrado nos escritos de Marx.

Em seu livro Soviet Marxism, Marcuse escreve que:

Em termos marxianos (mas certamente não no marxismo soviético), seria fácil identificar o elemento comum na organização política da indústria que milita contra o progresso da liberdade, ou seja, a escravização do homem por meio de seu trabalho, sua subordinação

\footnotetext{
${ }^{14}$ Segundo Marcuse, "o reino da liberdade é vislumbrado como residindo além do reino da necessidade: a liberdade não está dentro da 'luta pela existência'"' (MARCUSE, 1966, p. 195). Marx, por sua vez, escreve que "o reino da liberdade começa na verdade apenas onde cessa o trabalho, que é determinado por considerações mundanas e pela necessidade; assim, a verdadeira liberdade reside além da esfera da produção material [...]. Depois disto é que começa o desenvolvimento da energia humana que é um fim em si mesmo, o verdadeiro reino da liberdade, o qual, todavia, só pode de fato florescer com o reino da necessidade como sua base. A redução da jornada de trabalho é seu pré-requisito básico" (MARX, 1967, p. 820).

${ }^{15}$ Ver a respeito as palavras escritas por Marcuse em Eros and Civilization: "O tempo de trabalho, que é a maior parte do tempo de vida do indivíduo, é tempo penoso, porque o trabalho alienado é ausência de gratificação" (MARCUSE, 1966, p. 45); e, "por causa da duração do trabalho, que ocupa praticamente a existência inteira do indivíduo maduro, o prazer é 'suspenso' e a pena prevalece" (MARCUSE, 1966, p. 35). É interessante comparar essas palavras de Marcuse com aquelas escritas por Marx, mostradas na nota de rodapé anterior. Para ambos, a redução da jornada de trabalho, condição necessária para libertar o homem e a mulher da luta cotidiana pela existência, seria uma tarefa da revolução comunista.
} 
|36 |

Marcuse e o conceito de trabalho

ao seu próprio trabalho objetificado (MARCUSE, 1958,

p. 196-7).

Ou seja, o elemento crítico do marxismo parece ter desaparecido no marxismo soviético, que lida com o problema do trabalho de maneira muito similar ao que se faz no capitalismo ocidental (MARCUSE, 1958, p. 195-209).

Na concepção de Marx, Marcuse nos assegura, "liberdade política e intelectual pressupõe a libertação da luta diária pelas necessidades da vida" (MARCUSE, 1958, p. 208), enquanto a luta incessante para "ganhar a própria sobrevivência", que compele o homem a despender praticamente todo seu tempo e energia na aquisição das necessidades da vida, como ocorria na então União Soviética, pertence necessariamente ao reino do trabalho alienado (MARCUSE, 1958, p. 208).

Segundo Marcuse, o conteúdo e o valor do socialismo

\begin{abstract}
devem ser determinados pelo tempo livre ao invés de tempo de trabalho, ou seja, o homem só retorna a si mesmo fora e "além" de todo o reino da produção material para meras necessidades da vida (MARCUSE, 1958, p. 235).
\end{abstract}

Marcuse acrescenta que, em contraste com essa concepção, "o trabalho moral soviético não reconhece qualquer diferença de valor entre trabalho alienado e trabalho não alienado" (MARCUSE, 1958, p. 238). Afirma também que na sociedade soviética o tempo de trabalho continua sendo não só o parâmetro através do qual a riqueza social é medida, mas também a forma pela qual a população obtém os meios de vida, isto é, via trabalho assalariado (MARCUSE, 1958, p. 238).

Da análise que Marcuse faz do marxismo soviético, podemos concluir que o problema do trabalho alienado, assim como do homem alienado, não foi resolvido pela revolução comunista que ocorreu na Rússia, a despeito da transformação dos meios de produção, pelo menos do ponto 
de vista legal, em propriedade coletiva (MARCUSE, 1958). Em outras palavras, isto quer dizer que para a abolição do trabalho alienado é preciso algo mais que a simples abolição da propriedade privada.

Para concluir, penso que é necessário acrescentar que a discussão acima também deixa aberta a possibilidade de se indagar até que ponto é pertinente conceber o trabalho como uma categoria ontológica e, ao mesmo tempo, também buscar a sua abolição. Se o trabalho, no sentido ontológico, é uma constante humana, ele jamais poderá ser abolido. Mas justamente por isso, é preciso diferenciá-lo do trabalho assalariado, que é uma realidade histórica do capitalismo e, portanto, passível de ser abolido. Marcuse tenta diferenciar o trabalho enquanto categoria ontológica do trabalho alienado; mas não consegue ser bem-sucedido porque, ao mesmo tempo, ele concebe o trabalho como um conceito ontológico, mas que é também historicamente determinado.

Aliás, isto pode ser visto na ambiguidade com que Marcuse emprega a palavra trabalho (labor), que em muitos dos seus escritos parece ter mais de um significado. ${ }^{16}$ Fica, assim, a sensação de que ele tem dificuldade em resolver com clareza as diferenças, por exemplo, entre trabalho (labor) e trabalho alienado (alienated labor), assim como entre trabalho (labor) e obra (work). ${ }^{17}$

\footnotetext{
${ }^{16}$ David Held também chama atenção para essas dificuldades e ambiguidades do conceito de trabalho de Marcuse: "Essas concernem, primeiro, ao status do trabalho: não está sempre claro se trabalho (labor) é uma categoria ontológica per si ou uma categoria da existência humana. Segundo, a diferença entre os conceitos de trabalho de Hegel e de Marx não estão sempre bem estabelecidas. Terceiro, Marcuse erradamente justapõe trabalho (labor), um 'produto da necessidade', com diversão, uma 'expressão da liberdade'” (HELD, 1980, p. 451).

${ }^{17}$ Embora com preocupações diferentes das de Marcuse, Hannah Arendt conseguiu ser mais efetiva na distinção entre labor e work, ao associar o primeiro às atividades de manutenção da vida e que se esgotam no próprio ato de consumo, enquanto vincula o segundo às atividades que se caracterizam
} 
|38|

Marcuse e o conceito de trabalho

Isto, no entanto, não diminui a importância de sua contribuição pioneira, que certamente ajudou a pavimentar o caminho para os debates posteriores, sobretudo a partir da década de 1980, a respeito da crise da sociedade do trabalho. Ou seja, o debate atual sobre a emergência do imaterial, em grande medida inspirado em releituras dos Grundrisse de Marx (cf. MARX \& ENGELS, 1986; 1987), teve em Marcuse um dos pioneiros, como testemunha sua discussão do trabalho alienado em Razão e revolução (MARCUSE, 1960).

Embora os protagonistas atuais desse debate sobre trabalho imaterial raramente façam menção a Marcuse, não dá para negar que ele foi um dos primeiros a tratar do tema da abolição do trabalho com base na leitura daquele texto de Marx - no qual ele usa a expressão "general intellect", base de grande parte das formulações a respeito do trabalho imaterial -, tema caro a autores como André Gorz, Antonio Negri, Robert Kurz e Moishe Postone, entre outros (MARX \& ENGELS, 1986; 1987). ${ }^{18}$

Como um dos principais teóricos da nova esquerda, por outro lado, Marcuse abordou problemas que só mais tarde entraram de fato na agenda dos debates acadêmicos e das lutas dos movimentos sociais e culturais, como identidade e subjetividade, sem contar sua incursão pela psicanálise freudiana em Eros e civilização (MARCUSE, 1966a), provavelmente um de seus livros mais lidos. Enfim, tudo isto indica que Marcuse continua sendo um autor atual.

por deixar traços de permanência e conter algo da personalidade de quem as executa. Ela também relaciona as duas atividades, respectivamente, ao reino da necessidade e ao reino da liberdade. Para ela, no entanto, o trabalho moderno é quase uma simbiose dessas duas atividades (ARENDT, 1958).

${ }^{18}$ Ver por exemplo: Gorz (2005), Hardt \& Negri (2003), Kurz (1992) e Postone (1993). 


\section{Referências}

ARENDT, H. The Human Condition. Chicago: Chicago University Press, 1958.

BERKI, R. N. On the Nature and Origins of Marx's Concept of Labor. Political Theory, vol. 7, n. 1, p. 35-56, 1979.

DONZELOT, J. L'invention du social. Paris: Éditions du Seuil, 1994.

GORZ, A. O imaterial: conhecimento, valor e capital. São Paulo: Annablume, 2005.

HARDT, M.; NEGRI, A. Império. Rio de Janeiro: Editora Record, 2003.

HELD, D. Introduction to Critical Theory. Berkeley/Los Angeles: University of California Press, 1980.

KELLNER, D. Introduction to "On the Philosophical Foundation of the Concept of Labor". Telos, 16, p. 2-8, 1973.

Herbert Marcuse and the Crisis of Marxism. Berkeley: University of California Press, 1984.

KURZ, R. O colapso da modernização. São Paulo: Paz e Terra, 1992.

LOUREIRO, I. Herbert Marcuse, crítico do capitalismo tardio: reificação e unidimensionalidade. In: ALMEIDA, J.; BADER, $W$. Pensamento alemão no século XX: grandes protagonistas e recepção no Brasil, vol. 1. São Paulo: Cosac Naify, 2009, p. 203-235.

MARCUSE, H. Soviet Marxism. New York: Columbia University Press, 1958.

[1941] Reason and Revolution. Boston: Beacon Press, 1960.

Eros and Civilization. Boston: Beacon Press, 1966a.

One-dimensional Man. Boston: Beacon Press, 1966b. 
The Obsolescence of the Freudian Concept of Man. In: Five Lectures. Boston: Beacon Press, 1970, p. 44-61.

[1933] On the Philosophical Foundation of the Concept of Labor in Economics. Telos, 16, p. 9-37, 1973.

Ideias sobre uma teoria crítica da sociedade. Trad. Fausto Guimarães. Rio de Janeiro: Zahar Editores, 1981.

[1932] The Foundation of Historical Materialism. In: From Luther to Popper. Trans. Joris De Bres. London/New York: Verso, 1983, p. 1-48.

MARX, K. Capital, vol. 3. New York: International Publishers, 1967.

The Economic and Philosophic Manuscripts of 1844. In: TUCKER, R. C. (org.). The Marx-Engels Reader. New York/ London: W. W. Norton \& Company, 1978a, p. 66-125.

The Eighteenth Brumaire of Louis Bonaparte. New York: International Publishers, 1978b.

Wage Labour and Capital. In: TUCKER, R. C. (org.). The Marx-Engels Reader. New York/London: W. W. Norton \& Company, 1978c, p. 203-217.

MARX, K.; ENGELS, F. Collected Works, v. 28. New York: International Publishers, 1986. 1987.

Collected Works, v. 29. New York: International Publishers,

POSTONE, M. Time, Labor, and Social Domination. Cambridge: Cambridge University Press, 1993.

SCHMIDT AM BUSCH, H-C. Exteriorização e economia: A teoria hegeliana do trabalho e da sociedade civil. In: MERCURE, D.; SPURK, J. (orgs.). O trabalho na história do pensamento ocidental. Petrópolis: Vozes, 2003, p. 88-112. 
SILVA, J. P. Trabalho, cidadania e reconhecimento. São Paulo: Annablume, 2008.

VANDENBERGHE, F. Une histoire critique de la sociologie allemande: aliénation et réification, Tome II. Paris: La Découverte, 1998, p. 107-159. 